\title{
Ginsenoside Rg3 alleviates inflammation in a rat model of myocardial infarction via the SIRT1/NF-кB pathway
}

\author{
CHENCHEN TU*, BAOYAN WAN* and YONG ZENG \\ Department of Cardiology, Beijing Anzhen Hospital, Capital Medical University, Beijing 100029, P.R. China
}

Received July 4, 2019; Accepted June 5, 2020

DOI: $10.3892 /$ etm.2020.9368

\begin{abstract}
Inflammation serves an important role in myocardial infarction (MI). Ginsenoside $\operatorname{Rg} 3$ (Rg3), an activator of sirtuin 1 (SIRT1), has been identified to elicit anti-inflammatory

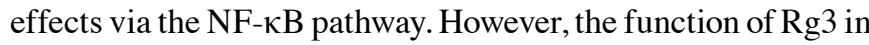
$\mathrm{MI}$ remains unknown. In the present study, a MI rat model was established by coronary artery ligation and treated with $\mathrm{Rg} 3$ to explore whether $\mathrm{Rg} 3$ could inhibit inflammation in MI rats by inhibiting the SIRT1/NF- $\kappa$ B pathway. At 28 days post-MI, it was identified that $\mathrm{Rg} 3$ not only decreased the ST-segment ECG values in MI rats, but also significantly decreased serum $\mathrm{LDH}, \mathrm{CK}-\mathrm{MB}$ and cTnI levels in MI rats. In addition, $\mathrm{Rg} 3$ also significantly decreased serum tumor necrosis factor $\alpha$ (TNF$\alpha$ ), interleukin (IL) $-1 \beta$ and IL- 6 levels and increased serum IL-10 levels in MI rats. In the heart tissues of the MI rats, Rg3 attenuated myocardial pathological changes and cell apoptosis caused by MI, decreased the gene expression levels of TNF- $\alpha$, IL- $1 \beta$ and IL- 6 , but increased the gene expression level of IL-10. In addition, the expression levels of the SIRT1 and transcription factor RelB proteins were significantly increased following Rg3 treatment, and the expression level of p-p65/p65 protein was significantly decreased in the heart tissues of MI rats with $\mathrm{Rg} 3$ treatment compared with that in heart tissues of MI rats without $\operatorname{Rg} 3$ treatment. In conclusion, $\mathrm{Rg} 3$ alleviates inflammation in a rat model of MI via the SIRT1/NF- $\kappa$ B pathway.
\end{abstract}

\section{Introduction}

Myocardial infarction (MI) is the primary cause of morbidity and mortality worldwide. Exercise training and pharmacological treatments are the important strategies to reduce the

Correspondence to: Dr Yong Zeng, Department of Cardiology, Beijing Anzhen Hospital, Capital Medical University, 2 Anzhen Road, Chaoyang, Beijing 100029, P.R. China

E-mail: zengyong1999@126.com

*Contributed equally

Key words: ginsenoside Rg3, inflammation, myocardial infarction, sirtuin $1 / \mathrm{NF}-\kappa \mathrm{B}$ harmful effects following MI $(1,2)$. When MI occurs, the cardiomyocytes suffer irreversible damage and necrosis due to hypoxia and a decreased supply of $\operatorname{ATP}(3,4)$. The necrotic cells activate the autoimmune system and lead to a severe inflammatory response after releasing their contents. On one hand, the release of inflammatory mediators initiates the repair of damaged tissues by the body $(5,6)$. Conversely, inflammatory cytokines could induce cardiomyocyte apoptosis, which further promotes the increase of inflammatory cytokines $(7,8)$. Therefore, the use of anti-inflammatory agents is an important facet of the treatment of patients with MI (9).

Following MI, in addition to lifestyle interventions, drug therapy is the cornerstone for improving survival and decreasing the incidence of new cardiovascular events (10). Compared with chemical drugs and biopharmaceuticals, the multi-component and multi-target nature of the compounds, and less adverse reactions, are the unique advantages of Traditional Chinese Medicine in treating diseases. Ginsenoside $\operatorname{Rg} 3$ ( Rg3) is an active component isolated from ginseng. It is a tetracyclic triterpenoid saponin, which can inhibit neovascularization, induce tumor cell apoptosis, inhibit inflammation and enhance immune function $(11,12)$. Previous studies have suggested that Rg3 not only inhibits the inflammatory response caused by lipopolysaccharide (13), but also improves cardiac function following MI/ (reperfusion) $\mathrm{R}$ via attenuating apoptosis and inflammation (14), and these effects are all associated with an Rg3-mediated inhibition of the $\mathrm{NF}-\kappa \mathrm{B}$ pathway $(13,14)$. In addition, a number of studies have identified that $\operatorname{Rg} 3$ is an activator of sirtuin 1 (SIRT1) in rats $(15,16)$. SIRT1 is a histone deacetylase widely expressed in human cells. It serves an important biological function by deacetylating multiple transcription factors $(17,18)$. Transcription factor p65 (p65) is an important marker of the activation of $\mathrm{NF}-\kappa \mathrm{B}$ signaling, which only functions following its acetylation. In inflammatory responses, SIRT1 deacetylates p65, thereby inhibiting the transcription of tumor necrosis factor- $\alpha$ (TNF- $\alpha$ ), interleukin (IL)- 6 and other inflammatory genes downstream of $\mathrm{NF}-\kappa \mathrm{B}$ (19). However, whether $\mathrm{Rg} 3$ can inhibit the NF- $\kappa \mathrm{B}$ pathway by activating SIRT1, and thereby inhibiting the inflammatory response caused by MI, remains unknown.

In the present study, a MI rat model was established by coronary artery ligation and then treated with Rg3. It was identified that $\mathrm{Rg} 3$ could attenuate inflammation in myocardial tissue and serum of rat MI rats by inhibiting the SIRT1/NF- $\kappa \mathrm{B}$ pathway, thereby protecting cardiac function in MI rats. 


\section{Materials and methods}

Animals and treatment. A total of 28 male SD rats (5-6 weeks old) weighing 165-200 g were used to generate the animal model in the present study (18). The animals were offered access to food and water ad libitum and housed in the animal experimental center of Capital Medical University in a 12: 12 h light: Dark cycle at $22 \pm 2^{\circ} \mathrm{C}$. Rats were randomly assigned to 4 groups: Sham; RG3; MI; and RG3 + MI. The rats in the sham and RG3 groups had no ligation of coronary artery, and the rats in the MI and RG3 + MI groups were used to establish the MI model by ligation of coronary arteries.

At 7 days prior to and 28 days after coronary artery ligation, the rats in the $\mathrm{Rg} 3$ and $\mathrm{Rg} 3$ + MI groups were administered 30 mg/kg/day Rg3 (cat. no., 64139; Sigma-Aldrich; Merck $\mathrm{KGaA}$ ) intragastrically for 7 days, and an equal amount of saline was used in the sham and MI groups. All animal protocols were approved by the Animal Care and Use Committee in Beijing Anzhen Hospital, Capital Medical University, and conformed with the guidelines of the National Institutes of Health (20).

Myocardial infarction rat model. Coronary artery ligation was used to establish a rat model of MI, as described previously (21). Briefly, the rats were anesthetized, and the depth of anesthesia was evaluated by observing the conjunctival reflex, tail pinch and eyelid reflexes (20). Then, a normal II lead electrocardiogram (ECG) was performed. For the surgical procedure, the skin on the left side of the sternum was prepared, disinfected, and a scalpel incision was made using a 10-0 purse string suture to quickly close the chest following surgery. The intercostal muscles between the 3rd to 4 th ribs were separated, revealing the heart. The coronary veins associated with the left coronary artery were identified between the left atrial appendage and the pulmonary artery cone. They were ligated with 6-0 non-invasive sutures at 2-3 mm below the left atrial appendage. The depth of the needle was maintained at $0.1 \mathrm{~cm}$ and the width was $0.2-0.3 \mathrm{~cm}$. The heart was placed back into the chest cavity through the intercostal space. The gas in the chest cavity was quickly squeezed to tighten the purse string suture for ligation. Then the incision was sutured. The sham operation and the RG3 groups were only threaded and not ligated. Significant elevation of the S-T segment or widening of the QRS complex was a sign of successful model establishment. Post-surgery intramuscular penicillin was administered continuously for 3 days to prevent infection. The rats were considered to be healthy by observing the skin, activity, food intake, excretion, abdominal respiration, external genitalia, and eyes following surgery. Concomitantly, the cardiac function of the rats was also evaluated by echocardiography and serum myocardial enzymes, and serum inflammatory factors were measured to assess levels of inflammation.

Hematoxylin \& eosin (H\&E) staining. On the 28th day after the MI model was constructed, the experimental rats were anesthetized by intraperitoneal injection of sodium pentobarbital $(30 \mathrm{mg} / \mathrm{kg})$, and the depth of anesthesia in the rats was evaluated by observing conjunctival reflex, tail pinch and eyelid reflexes. Following euthanasia by cervical dislocation, the chest cavity was opened to obtain the heart tissue and to collect aneurysm specimens. A portion of the specimen was dehydrated and paraffin-embedded, and the specimen was cut into $5 \mu \mathrm{m}$ slices using the CUT4062 serial slicer (SLEE medical GmbH). Paraffin sections were routinely dewaxed and washed with $H \& E$ staining kits for H\&E staining (cat. no., G1120; Beijing Solarbio Science \& Technology Co., Ltd.) as follows: The samples were dyed with hematoxylin for 5-10 min at room temperature, washed for 3-5 min , soaked with $0.5-1 \%$ hydrochloric acid in alcoholic solution for several seconds at room temperature, washed for 3-5 min, and then colored with alkaline aqueous solution for $1 \mathrm{~min}$, followed by washing with water for $10 \mathrm{~min}$, and examination using an optical microscope (LSM800; Olympus Corporation). Following staining, the slides were washed 1 or 2 times, stained with $0.5 \%$ eosin for $1-2 \mathrm{~min}$ at room temperature, dehydrated with alcohol (80\% ethanol for $30 \mathrm{sec}, 95 \%$ ethanol for $1 \mathrm{~min}, 95 \%$ ethanol for $1 \mathrm{~min}$, absolute ethanol for $3 \mathrm{~min}$ and absolute ethanol for $3 \mathrm{~min}$ ), washed with xylene, and sealed using a neutral resin. An LSM800 optical microscope (x200 magnification; Olympus Corporation) was used to observe the pathological changes in each slice following H\&E staining.

ELISA assay. Blood samples were collected from $\sim 1 \mathrm{~cm}$ capillaries underneath the eyelids, and the sera were obtained following centrifugation at $1,000 \mathrm{x} \mathrm{g}$ for $5 \mathrm{~min}$ at room temperature. Creatine kinase myocardial band (CK-MB; cat. no., XF2852b, Shanghai Xinfan Biotechnology Co., Ltd.), lactate dehydrogenase (LDH; cat. no. BC0685; Beijing Solarbio Science \& Technology Co., Ltd.), cardiac troponin-1 (cTnI; cat. no., ab246529; Abcam), IL-1 $\beta$ (cat. no., ab100768; Abcam), TNF- $\alpha$ (cat. no., ab100785; Abcam), IL-6 (cat. no., ab100772; Abcam) and IL-10 (cat. no., ab100765; Abcam) ELISA kits were used to detect the CK-MB, LDH, cTnI, IL-1 $\beta$, TNF- $\alpha$, IL- 6 and IL-10 levels in serum, respectively.

TUNEL assay. Tissues were fixed with $10 \%$ formalin solution at room temperature for $24 \mathrm{~h}$, and slices were prepared. Paraffin-embedded cardiac tissue sections were first dewaxed in xylene for 5-10 min at room temperature. Finally, they were immersed in $90 \%$ ethanol for $2 \mathrm{~min}, 70 \%$ ethanol for $2 \mathrm{~min}$ and distilled water for $2 \mathrm{~min}$. Then, the one-step TUNEL Apoptosis Detection kit (cat. no., C1088; Beyotime Institute of Biotechnology) was used to detect the levels of apoptosis in the heart tissue following the manufacturer's protocol. Nuclear counterstaining was performed for $5 \mathrm{~min}$ using DAPI ( $5 \mu \mathrm{g} / \mathrm{ml}$; Sigma-Aldrich; Merck KGaA) at room temperature. An LSM800 optical microscope (x200 magnification; Olympus Corporation) was used to observe apoptotic cells.

Reverse transcription-quantitative PCR (RT-qPCR). Levels of TNF- $\alpha$, IL-1 $\beta$, L- 6 and IL-10 in the rats were measured as described previously (22) with RT-qPCR using gene-specific TaqMan primer/probe sets in an ABI prism 7000 Sequence Detection System (Applied Biosystems). The total RNA was reverse transcribed into cDNA using a reverse transcription kit 
A

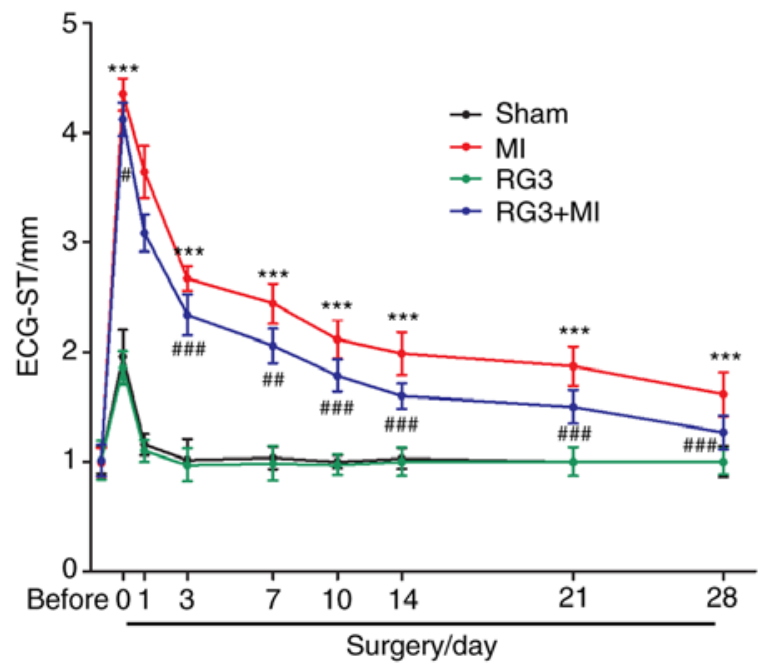

C

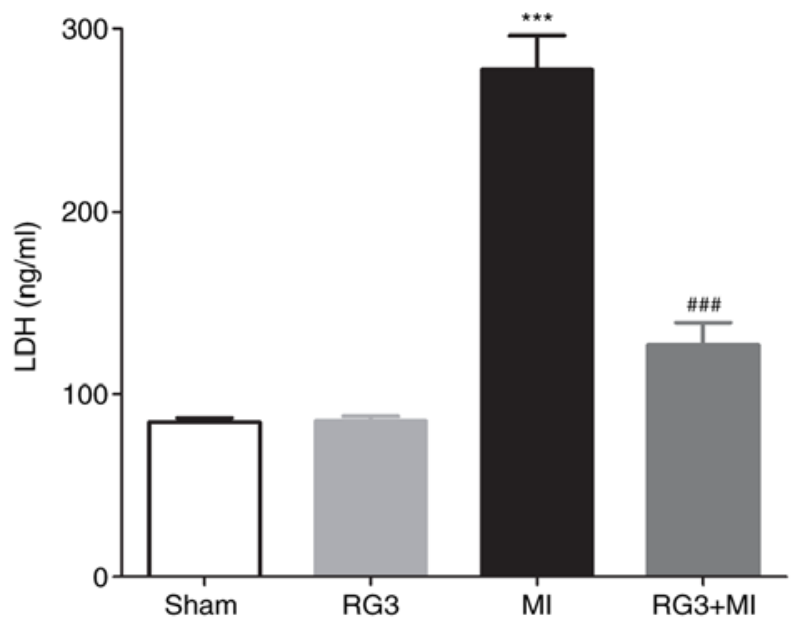

B

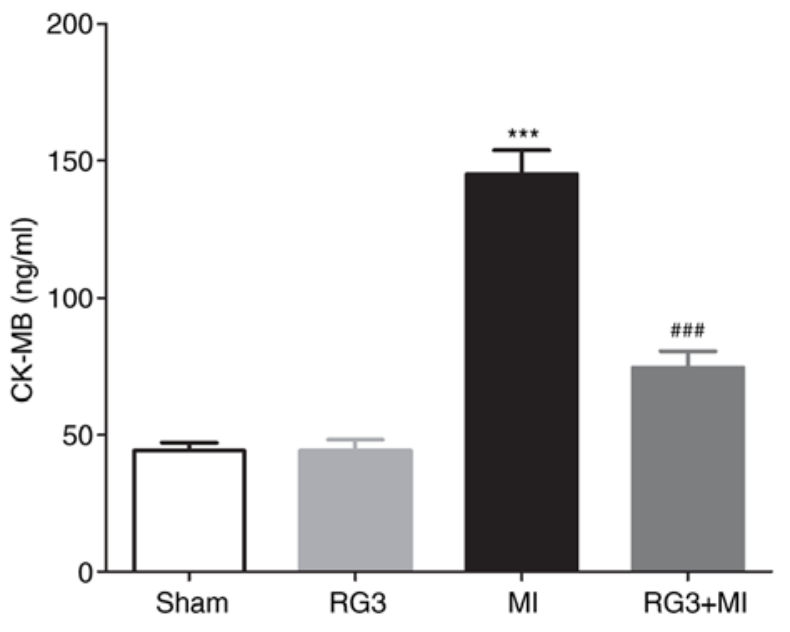

D

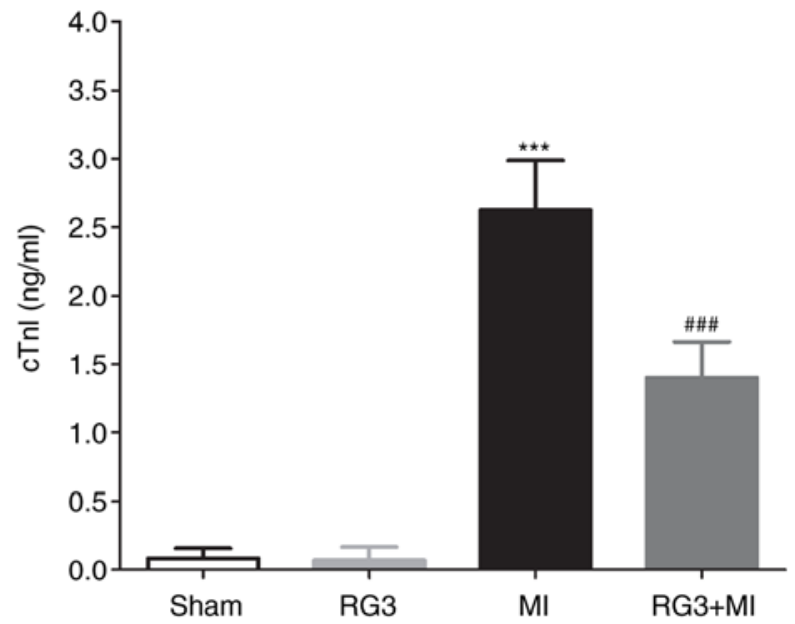

Figure 1. Effect of Rg3 on cardiac function in rats following MI. (A) The values of electrocardiograms in ST segment in different groups of rats at different times. (B-D) 28 days after MI, serum (B) CK-MB, (C) LDH and (D) cTnI levels in different groups of rats. There were 7 rats per group and 3 independent repetitions per measurement. ${ }^{* * *} \mathrm{P}<0.001$ vs. sham group. ${ }^{\#} \mathrm{P}<0.05,{ }^{\# \#} \mathrm{P}<0.01$ and ${ }^{\# \# \#} \mathrm{P}<0.001$ vs. MI group. Rg3, Ginsenoside Rg3; MI myocardial infarction; CK-MB, creatine kinase myocardial band; LDH, lactate dehydrogenase; cTnI, cardiac troponin-1.

(cat. no., RR036B; Takara Bio, Inc.) according to the manufacturer's protocol. Subsequently, a 20- $\mu$ l RT-qPCR system was prepared using the GoTaq qPCR Master Mix kit according to the manufacturer's protocol (cat. no., 638320; Takara Biotechnology, Co., Ltd.). GAPDH mRNA transcription was used as the internal loading control. The PCR primer sequences were as follows: TNF- $\alpha$ forward (F), 5'-CTGAACTTCGGG GTGATCGG-3'; TNF- $\alpha$ reverse (R): 5'-GGCTTGTCACTC GAATTTTGAGA-3'; IL-1 $\beta$ F, 5'-GAAATGCCACCTTTT GACAGTG-3'; IL-1 $\beta$ R, 5'-TGGATGCTCTCATCAGGACAG -3'; IL-6 F, 5'-TCTATACCACTTCACAAGTCGGA-3'; IL-6 R, 5'-GAATTGCCATTGCACAACTCTTT-3'; IL-10 F, 5'-GCT ATCGCCCGGTATAG-3'; and IL-10 R, 5'-GTTTCGCGT CGATATTAGC-3'; GAPDH F, 5'-AGGTCGGTGTGAACG GATTTG-3' and GAPDH R, 5'-GGGGTCGTTGATGGC AACA-3'. The thermocycling conditions for the qPCR were as follows: Initial denaturation $\left(94^{\circ} \mathrm{C}\right.$ for $\left.2 \mathrm{~min}\right) ; 40$ cycles of denaturation $\left(95^{\circ} \mathrm{C}\right.$ for $\left.30 \mathrm{sec}\right)$, annealing $\left(90^{\circ} \mathrm{C}\right.$ for $\left.5 \mathrm{sec}\right)$ and elongation $\left(65^{\circ} \mathrm{C}\right.$ for $\left.30 \mathrm{sec}\right)$; and a final extension $\left(72^{\circ} \mathrm{C}\right.$ for $60 \mathrm{sec}$ ). The $2^{-\Delta \Delta \mathrm{Cq}}$ method was used to quantify gene expression levels (23).
Western blot analysis. Protein levels were analyzed by western blot analysis, as described previously (22). GAPDH protein transcription was used as the internal loading control. RIPA Lysis Buffer (cat. no. P0013K; Beyotime Institute of Biotechnology) was used to lyse fibroblast-like synoviocytes and synovial tissue, and the BCA Protein Assay kit (cat. no. P0010S; Beyotime Institute of Biotechnology) was used to measure lysate protein concentration. A total of $50 \mu \mathrm{g}$ protein/lane in cell lysates were separated by $10 \%$ SDS-PAGE and then transferred to PVDF membranes, which were then blocked with 5\% skim milk powder for $1 \mathrm{~h}$ at room temperature. The primary antibodies in the present study were as follows for overnight incubation at $4^{\circ} \mathrm{C}$ : Anti-p65 phosphorylated (p)-S636 (cat. no. ab86299; 1:5,000; Abcam) and anti-GAPDH (cat. no. ab9484; 1:3,000; Abcam). The following secondary antibodies were used for $1 \mathrm{~h}$ incubation at room temperature: Horseradish peroxidase (HRP)-conjugated goat anti-rabbit immunoglobulin $\mathrm{G}(\mathrm{IgG})$ H\&L (cat. no. ab6721; 1:3,000; Abcam) and HRP-conjugated goat anti-mouse IgG H\&L (cat. no. ab6789; 1:3,000; Abcam. ImageJ v1.8.0 (National Institutes of Health) was used to analyze protein gray value. 
A

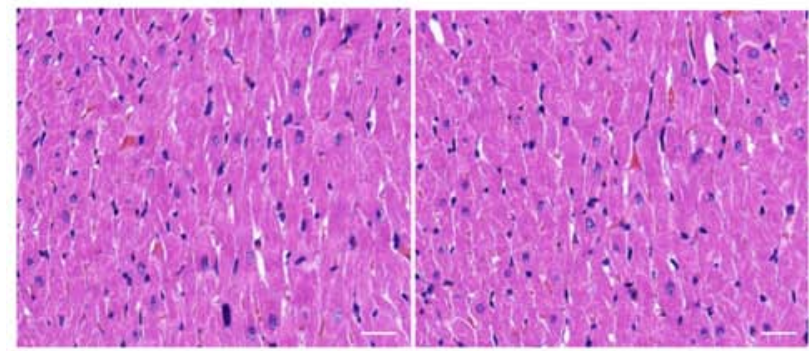

E

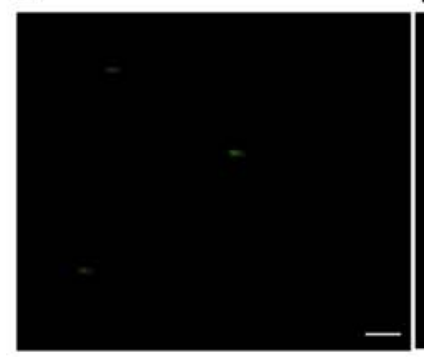

F

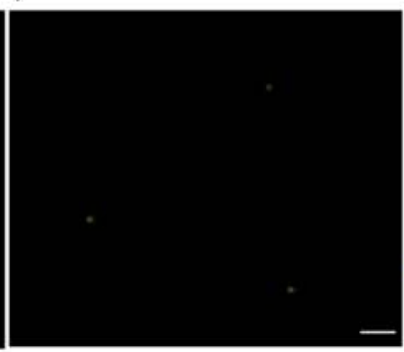

C

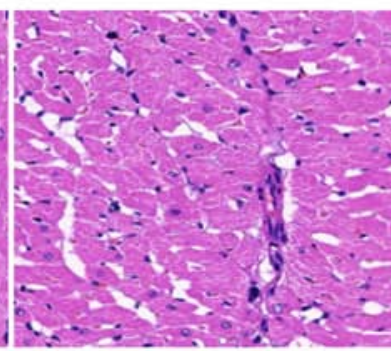

G

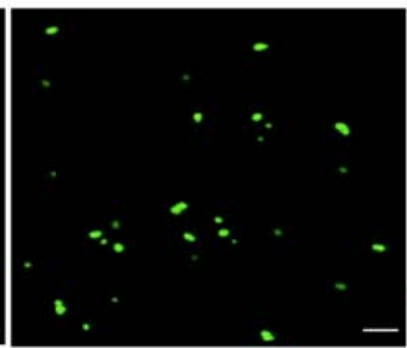

D

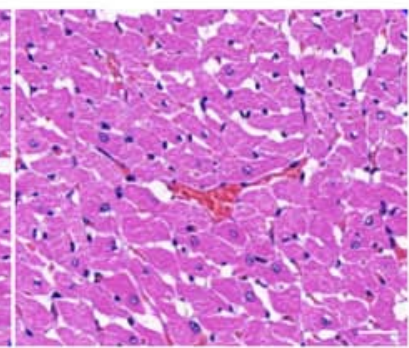

$\mathrm{H}$

Figure 2. Effect of Rg3 on pathological changes of heart tissues in rats following MI. (A-D) Hematoxylin \& eosin staining was used to observe pathological changes in the heart tissues of the (A) sham, (B) Rg3, (C) MI and (D) Rg3 + MI groups of rats in 28 days after MI. (E-H) The cell apoptosis was measured in the heart tissues of the (E) sham, (F) $\mathrm{Rg} 3,(\mathrm{G}) \mathrm{MI}$ and $(\mathrm{H}) \mathrm{Rg} 3+\mathrm{MI}$ groups of rats in 28 days after MI. There were 7 rats per group and 3 independent repetitions per measurement. Scale bar $=50 \mu \mathrm{m}$. Rg3, Ginsenoside Rg3; MI, myocardial infarction.
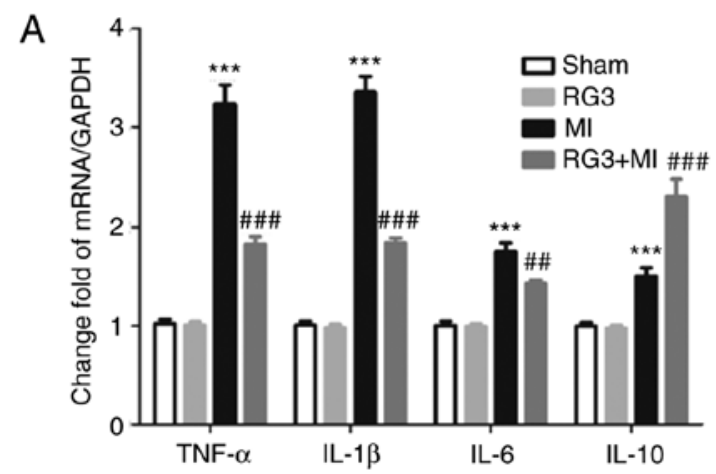

B

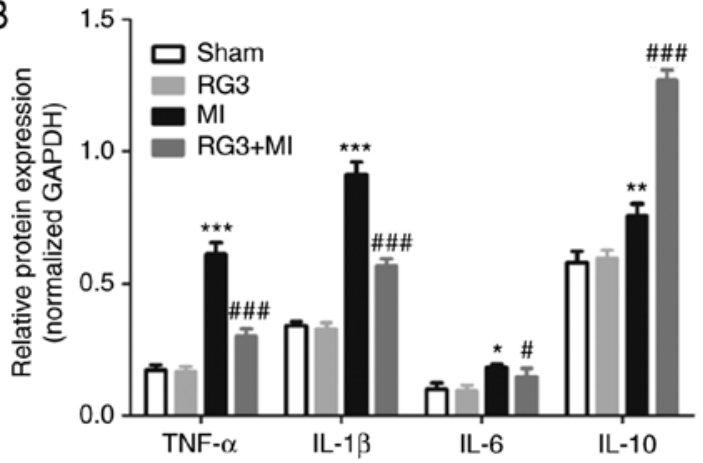

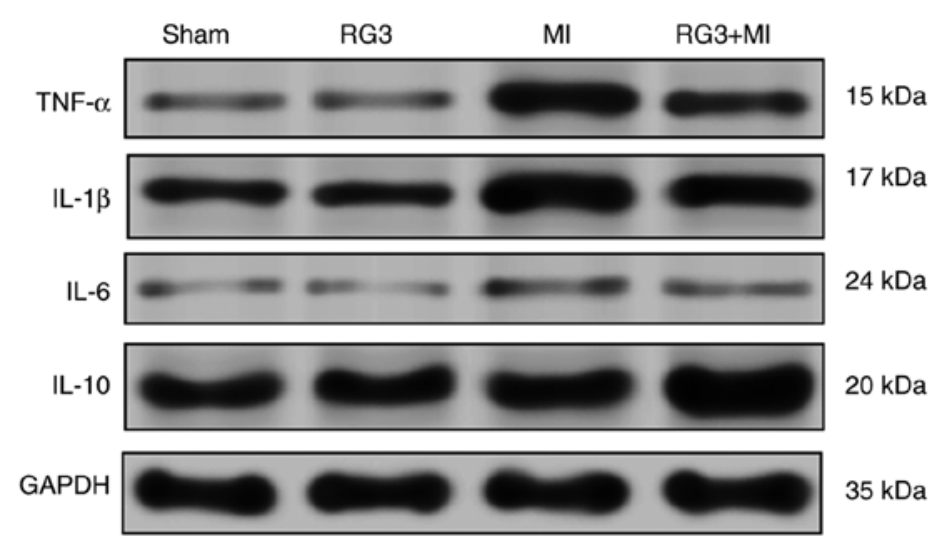

Figure 3. Effect of $\operatorname{Rg} 3$ on inflammatory factors in heart tissues in rats following MI. (A and B) At 28 days post-MI, the expression levels of TNF- $\alpha$, IL-1 $\beta$, IL- 6 and IL-10 mRNA in the heart tissues of rats were measured by RT-qPCR, and proteins were measured by western blot. There were 7 rats per group and 3 independent repetitions per measurement. ${ }^{*} \mathrm{P}<0.05,{ }^{* *} \mathrm{P}<0.01$ and ${ }^{* * * *} \mathrm{P}<0.001$ vs. sham group. ${ }^{*} \mathrm{P}<0.05,{ }^{\# \#} \mathrm{P}<0.01$ and ${ }^{\# \# \#} \mathrm{P}<0.001$ vs. MI group. Rg3, Ginsenoside Rg3; MI, myocardial infarction; TNF- $\alpha$, tumor necrosis factor $\alpha$; IL, interleukin.

Statistical analysis. Data were presented as the mean \pm SD. SPSS 20.0 (IBM Corp) software was used to analysis the data in the present study. A Student's t-test was used to compare differences between two groups, and multiple groups were compared using one-way ANOVA followed by a Tukey's post hoc test. $\mathrm{P}<0.05$ was considered to indicate a statistically significant difference. 
A

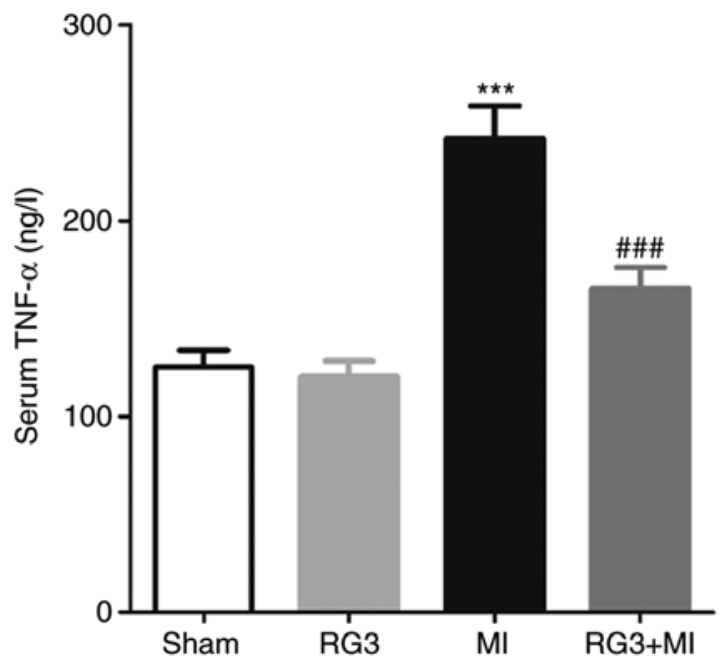

C

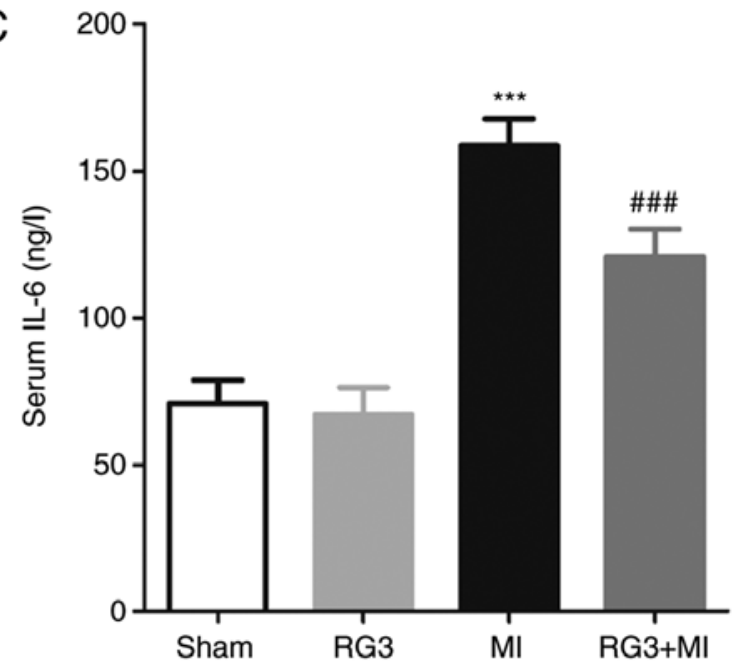

B

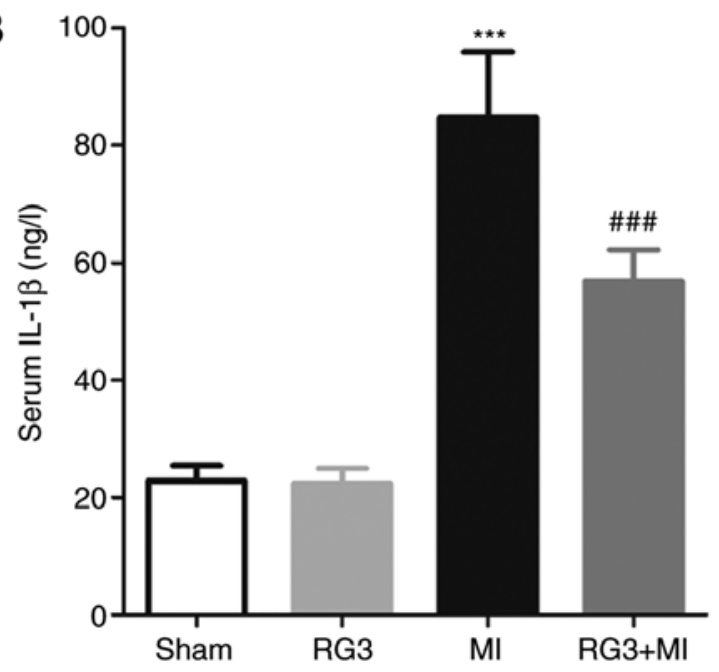

D

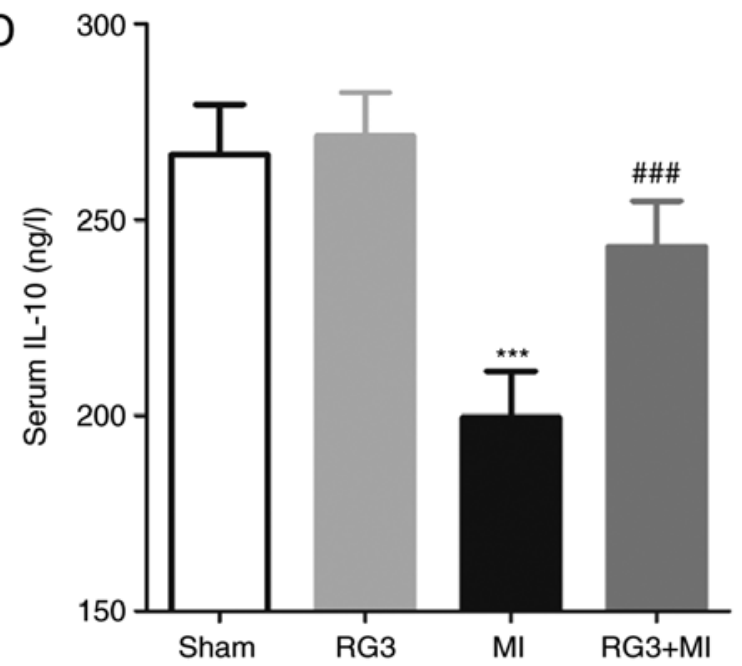

Figure 4. Effect of Rg3 on serum inflammatory factors in rats following MI. (A-D) At 28 days post-MI, serum (A) TNF- $\alpha$, (B) IL-1 $\beta$, (C) IL-6 and (D) IL-10 levels in different groups. There were 7 rats per group and 3 independent repetitions per measurement. ${ }^{* * *} \mathrm{P}<0.001$ vs. sham group. ${ }^{\# \# \#} \mathrm{P}<0.001$ vs. MI group. Rg3, Ginsenoside Rg3; MI, myocardial infarction; TNF- $\alpha$, tumor necrosis factor $\alpha$; IL, interleukin.

\section{Results}

Rg3 enhances cardiac function in rats following MI. A rat MI model was established by coronary artery ligation, and as shown in Fig. 1A, the S-T segment of the ECG in the rats was significantly increased following coronary artery ligation compared with the sham group. This indicated that the MI model was successfully established. It was also identified that $\operatorname{Rg} 3$ could significantly attenuate the increase in rat electrocardiogram S-T values caused by coronary artery ligation. On 28th day post-MI, the serum levels of CK-MB, $\mathrm{LDH}$ and cTnI in the RG3 + MI rats were significantly decreased compared with those in the MI group (Fig. 1B-D). In addition, H\&E staining was used to detect pathological changes in rat heart tissue 28 days following MI. It was observed that there were a number of pathological changes in the heart tissue of the MI group (Fig. 2C) compared with the sham group (Fig. 2A) and the RG3 group (Fig. 2B), such as myocardial tissue injury, and disordered cell and muscle bundle arrangement. There were a large number of infiltrating inflammatory cells, and the nuclei were dissolved, disappeared or necrotic. However, Rg3 was demonstrated to significantly alter the extent of pathological damage in the heart tissue caused by MI. In the RG3 + MI group (Fig. 2D), the muscle bundles were arranged neatly, the cell morphology was intact, and the level of inflammatory cell infiltration was decreased. It was also observed that the level of cell apoptosis in the RG3 + MI group was significantly decreased compared with that in the MI group (Fig. 2E-H). These data suggested that $\mathrm{Rg} 3$ protected cardiac function in rats following MI.

Rg3 attenuates inflammation of heart tissue in rats following $M I$. The results of the H\&E staining protocol demonstrated that $\mathrm{Rg} 3$ attenuated MI-induced inflammatory cell infiltration in the heart tissues of rats. On the 28th day post-MI, the expression of inflammatory factor in the heart tissue in rats was also detected, and it was identified that the mRNA and protein expression levels of TNF- $\alpha$, IL-1 $\beta$ and IL- 6 in the heart tissues of the MI rats were significantly increased compared with that in RG3 + MI group (Fig. 3). The expression of IL-10 was demonstrated to be the opposite. This 


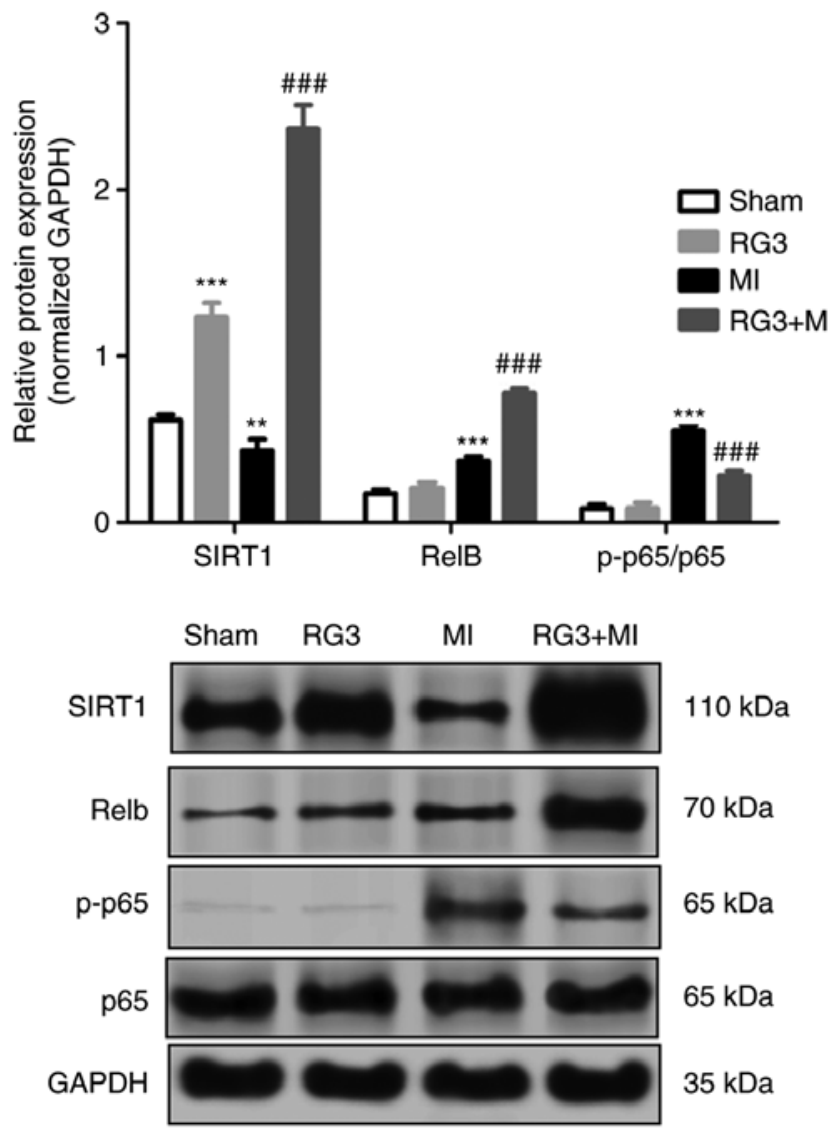

Figure 5. Effect of Rg3 on the SIRT1/NF- $\mathrm{BB}$ pathway of heart tissue in rats following MI. At 28 days post-MI, the expression levels of SIRT1, RelB and $\mathrm{p}-\mathrm{p} 65 / \mathrm{p} 65$ protein in heart tissues of rats were measured by western blot analysis. There were 7 rats per group and 3 independent repetitions per measurement. ${ }^{* *} \mathrm{P}<0.01$ and ${ }^{* * *} \mathrm{P}<0.001$ vs. sham group. ${ }^{\# \# \#} \mathrm{P}<0.001$ vs. MI group. Rg3, Ginsenoside Rg3; MI, myocardial infarction; SIRT1, sirtuin 1; RelB, transcription factor RelB; p65, transcription factor p65; p-, phosphorylated.

indicated that $\operatorname{Rg} 3$ attenuated inflammation of heart tissue in rats after $\mathrm{MI}$.

Rg3 attenuates the levels of serum inflammatory markers in rats following MI. On the 28th day post-MI, the levels of TNF- $\alpha$, IL-1 $\beta$, IL- 6 and IL-10 in the serum of rats were measured, and it was identified that the serum levels of TNF- $\alpha$, IL-1 $\beta$ and IL-6 in the RG3 + MI group were significantly decreased compared with those in the MI group, and the serum levels of IL-10 were significantly increased compared with the MI group (Fig. 4).

Rg3 inhibits the SIRTI/NF- $\kappa B$ pathway in rat heart tissue following $M I$. Western blot analysis was used to measure the expression levels of proteins in the heart tissues, and the results are shown in Fig. 5. The expression level of SIRT1 protein was significantly increased following $\mathrm{Rg} 3$ treatment in the RG3 group compared with the sham group, and in the RG3 + MI group compared with the MI group, but the expression level of SIRT1 protein in the MI group was significantly compared with that in the sham group. Compared with the MI group, the expression of transcription factor RelB (RelB) was significantly increased, and the expression of p-p65/p65 was significantly decreased.

\section{Discussion}

Coronary artery ligation is a standardized and universal model for the establishment of animal MI rat models to assess the protective/preventive effects of various cardioprotective plant components (21). Therefore, a MI rat model was established by coronary artery ligation in the present study. In cardiac ischemia, different myocardial enzymes become dysregulated, and the most commonly dysregulated enzymes are $\mathrm{LDH}, \mathrm{CKMB}$ and cTnI (24), accompanied by abnormal changes in ECG readings, such as an elevated S-T segment (25). Therefore, both myocardial enzymes and ECG can be used as specific indicators of MI. In the present study, it was identified that following coronary artery ligation, the ECG-ST value of the MI model rats was significantly increased compared with that of the sham group rats, indicating that the MI model was successfully established. In addition, it was observed that the serum LDH, CKMB and cTnI levels in the MI group were significantly increased compared with that in sham group, and $\mathrm{Rg} 3$ treatment could decrease them. The same effect was observed in the ECG-ST value. Compared with the MI group, H\&E staining indicated that the level of inflammatory cell infiltration of the myocardial tissue was decreased in the RG3 + MI group, the cell morphology integrity was improved, and the muscle bundles were arranged neatly. This indicated that Rg3 may decrease CKMB, LDH and cTnI leakage due to myocardial ischemia and reduce cardiomyocyte damage to some extent.

Inflammatory reactions are closely associated with the occurrence and development of acute MI. On one hand, the release of inflammatory mediators initiates the repair of the damaged tissues (26). Conversely, inflammatory reactions continuously induce matrix degradation and apoptosis of cardiomyocytes (27). Following MI, the inflammatory regulatory system is activated by factors including ischemia and hypoxia, inducing myocardial cell apoptosis and myocardial fibrosis. In order to remove necrotic cells, the body further activates the inflammatory response, leading to compensatory deterioration of cardiac function, such as myocardial remodeling (27). Therefore, inhibition of inflammation in the body following $\mathrm{MI}$ is one of the methods used to treat MI. $\mathrm{Rg} 3$ is one of the main active ingredients extracted from ginseng. Recent studies have suggested that $\operatorname{Rg} 3$ has the effect of inhibiting inflammation of cells in vitro $(28,29)$, and also has anti-inflammatory effects in animal models of MI/R (14) or lipopolysaccharide-induced learning and memory impairment in rats (13).

In the present study, it was identified that $\operatorname{Rg} 3$ not only decreased the serum levels of TNF- $\alpha$, IL-1 $\beta$ and IL- 6 and increased the serum IL-10 levels, but also decreased the expression levels of TNF- $\alpha$, IL- $1 \beta$ and IL- 6 gene and increased the serum IL-10 mRNA expression in the heart tissues of MI rats. IL-6 is a glycoprotein produced by both lymphocytes and non-lymphocyte cells, which regulates the synthesis of hepatic C-reactive protein. It increases the expression of adhesion molecules between cardiomyocytes, promoting platelet aggregation, and promoting smooth muscle cells proliferation and release of inflammatory factors such as IL-1 $\beta$ and TNF- $\alpha$ (30), while IL-1 $\beta$ and TNF- $\alpha$ enhance leukocyte chemotaxis and directly damage endothelial cells (31), which participate in the 
whole process response of MI inflammation. It was demonstrated that IL-10 is firstly synthesized and secreted by murine $\mathrm{CD}^{+} \mathrm{T}$ helper type 2 cells and had the function of inhibiting IFN- $\gamma$ synthesis by $\mathrm{T}$ helper type $1 \mathrm{~T}$ cells (32). As the study progressed $(33,34)$, the immunological characteristics of IL-10 were gradually revealed. The main cells for synthesizing IL-10 were monocytes and macrophages, but a number of other cells can also synthesize IL-10, including $\mathrm{CD}^{+}$and $\mathrm{CD}^{+}$ $\mathrm{T}$ cells, and $\mathrm{B}$ cells. In the immune system, IL-10 has the ability to inhibit the proliferation of antigen-specific $\mathrm{T}$ cells, the formation of antigen-presenting cells, and the synthesis and expression of inflammatory cytokines and inflammatory mediators. Taken together, IL-10 is a cytokine that inhibits the inflammatory response and elicits immunosuppressive effects in the body (35). Therefore, IL-10 is widely used in the treatment of autoimmune diseases as a natural immunosuppressive agent $(36,37)$.

The present study also identified that $\mathrm{Rg} 3$ not only increased the expression levels of SIRT1 and RelB proteins, but also decreased the expression of p-p65 protein. SIRT1 is a histone deacetylase that was widely expressed in human cells. It performs important biological functions by deacetylating multiple transcription factors, such as p53 (38), mitochondrial uncoupling protein 2 (39), histone acetyltransferase p300 (40) and $\mathrm{NF}-\kappa \mathrm{B}$ (41). p65 is an important component of $\mathrm{NF}-\kappa \mathrm{B}$, which only functions following its acetylation. In inflammatory responses, SIRT1-deacetylated p65 inhibits the transcription of TNF- $\alpha$, IL- 6 and other inflammatory genes downstream of NF- $\kappa \mathrm{B}$ (41), which is an important protein in the Toll-like receptors/NF- $\kappa \mathrm{B}$ signaling pathway. Its phosphorylationmediated translocation from the cytoplasm to the nucleus is an important marker of activation of NF- $\kappa \mathrm{B}$ signaling pathway.

$\mathrm{NF}-\kappa \mathrm{B}$ is a key transcription factor that mediates the release of inflammatory factors. It exists in vascular endothelial cells, vascular smooth muscle cells and cardiomyocytes, and participates in the occurrence and development of cardiovascular diseases $(42,43)$. Under normal physiological conditions, NF- $\kappa \mathrm{B}$ binds to the inhibitory protein $\mathrm{I} \kappa \mathrm{B}$ in the form of a homodimer and is inactive. When stimulated by various pathological factors, $\mathrm{NF}-\kappa \mathrm{B}$ and $\mathrm{I} \kappa \mathrm{B}$ are activated by phosphorylation and transferred to the nucleus, where they bind to specific target genes, regulate target gene transcription and release associated inflammatory factors, such as IL-1 $\beta$, IL- 6 and TNF- $\alpha$. The release of IL-1 $\beta$, TNF- $\alpha$ and IL- 6 also serves as a feedback signal for NF- $\mathrm{NB}$ and maintains the activity of $\mathrm{NF}-\kappa \mathrm{B}$, which causes a feedback cycle of myocardial injury $(41,42)$. SIRT1 inhibits NF- $\kappa \mathrm{B}$ activation by inhibiting $\mathrm{NF}-\kappa \mathrm{B}$ entry into the nucleus.

Therefore, in the present study, it was concluded that $\mathrm{Rg} 3$, as an activator of SIRT1, inhibited the activation of NF- $\kappa$ B pathway by activating the expression of SIRT1 in rats, thereby inhibiting the inflammatory response in MI rats.

\section{Acknowledgements}

Not applicable.

\section{Funding}

No funding was received.

\section{Availability of data and materials}

The datasets used and/or analyzed during the present study are available from the corresponding author on reasonable request.

\section{Authors' contributions}

YZ designed and performed the study and wrote the article. CT and BW performed the data collection and analysis. All authors read and approved the final manuscript and agree to be accountable for all aspects of the research in ensuring that the accuracy or integrity of any part of the work are appropriately investigated and resolved.

\section{Ethics approval and consent to participate}

This study was reviewed and approved by the Ethics Committee of Beijing Anzhen Hospital, Capital Medical University.

\section{Patient consent for publication}

Not applicable.

\section{Competing interests}

The authors declare that they have no competing interests.

\section{References}

1. Mangion K, Gao H, Husmeier D, Luo X and Berry C: Advances in computational modelling for personalised medicine after myocardial infarction. Heart 104: 550-557, 2017

2. Heusch G and Gersh BJ: The pathophysiology of acute myocardial infarction and strategies of protection beyond reperfusion: A continual challenge. Eur Heart J 38: 774-784, 2017.

3. Boersma E, Mercado N, Poldermans D, Gardien M, Vos J and Simoons ML: Acute myocardial infarction. Lancet 361: 847-858, 2003.

4. Reed GW, Rossi JE and Cannon CP: Acute myocardial infarction. Lancet 389: 197-210, 2016.

5. Michaels AD, Gibson CM and Barron HV: Microvascular dysfunction in acute myocardial infarction: Focus on the roles of platelet and inflammatory mediators in the no-reflow phenomenon. Am J Cardiol 85: 50B-60B, 2000.

6. Maier W, Altwegg LA, Corti R, Gay S, Hersberger M, Maly FE, Sütsch G, Roffi M, Neidhart M, Eberli FR, et al: Inflammatory markers at the site of ruptured plaque in acute myocardial infarction: Locally increased interleukin- 6 and serum amyloid A but decreased C-reactive protein. Circulation 111: 1355-1361, 2005.

7. Pop M, Qi X, Barry J, Strauss BH, Wright GA and Ghugre NR: Hemorrhage promotes inflammation and myocardial damage following acute myocardial infarction. J Cardiovasc Magn Reson 16 (Suppl 1): O72, 2014.

8. Westman PC, Lipinski MJ, Luger D, Waksman R, Bonow RO, Wu E and Epstein SE: Inflammation as a driver of adverse left ventricular remodeling after acute myocardial infarction. J Am Coll Cardiol 67: 2050-2060, 2016.

9. Ong SB, Hernández-Reséndiz S, Crespo-Avilan GE, Mukhametshina RT, Kwek XY, Cabrera-Fuentes HA and Hausenloy DJ: Inflammation following acute myocardial infarction: Multiple players, dynamic roles, and novel therapeutic opportunities. Pharmacol Ther 186: 73-87, 2018.

10. Eindhoven DC, Hilt AD, Zwaan TC, Schalij MJ and Borleffs CJW: Age and gender differences in medical adherence after myocardial infarction: Women donotreceive optimal treatment-The Netherlands claims database. Eur J Prev Cardiol 25: 20474873177444363, 2017.

11. Sun HY, Lee JH, Han YS, Yoon YM, Yun CW, Kim JH, Song YS and Lee SH: Pivotal roles of ginsenoside Rg3 in tumor apoptosis through regulation of reactive oxygen species. Anticancer Res 36: 4647-4654, 2016. 
12. Tang YC, Yan Z, Jin Z, Zhi Q, Wu MY, Gong FR, Shen M, Liu L, Tao M, Shen B, et al: Ginsenoside Rg3 targets cancer stem cells and tumor angiogenesis to inhibit colorectal cancer progression in vivo. Int J Oncol 52: 127-138, 2018.

13. Lee B, Sur B, Park J, Kim SH, Kwon S, Yeom M, Shim I, Lee H and Hahm DH: Ginsenoside Rg3 alleviates lipopolysaccharideinduced learning and memory impairments by anti-inflammatory activity in rats. Biomol Ther (Seoul) 21: 381-390, 2013.

14. Zhang LP, Jiang YC, Yu XF, Xu HL, Li M, Zhao XZ and Sui DY: Ginsenoside Rg3 improves cardiac function after myocardial ischemia/reperfusion via attenuating apoptosis and inflammation. Evid Based Complement Alternat Med 2016: 6967853, 2016.

15. Yang JL, Ha TK, Dhodary B, Kim KH, Park J, Lee CH, Kim YC and Oh WK: Dammarane triterpenes as potential SIRT1 activators from the leaves of Panax ginseng. J Nat Prod 77: 1615-1623, 2014.

16. Wang Y, Chen Y, Wang H, Cheng Y and Zhao X: Specific turn-on fluorescent probe with aggregation-induced emission characteristics for SIRT1 modulator screening and living-cell imaging. Anal Chem 87: 5046-5049, 2015.

17. Kauppinen A, Suuronen T, Ojala J, Kai K and Salminen A: Antagonistic crosstalk between NF-kB and SIRT1 in the regulation of inflammation and metabolic disorders. Cell Signal 25 : 1939-1948, 2013

18. Jankowski M, Bissonauth V, Gao L, Gangal M, Wang D, Danalache B, Wang Y, Stoyanova E, Cloutier G, Blaise G and Gutkowska J: Anti-inflammatory effect of oxytocin in rat myocardial infarction. Basic Res Cardiol 105: 205-218, 2010.

19. Chen GD, Yu WD and Chen XP: SirT1 activator represses the transcription of TNF- $\alpha$ in THP-1 cells of a sepsis model via deacetylation of H4K16. Mol Med Rep 14: 5544-5550, 2016.

20. National Research Council. Guide for the care and use of laboratory animals. National Academies Press, 2010

21. Sun Q, Kang Z, Cai J, Liu W, Liu Y, Zhang JH, Denoble PJ, Tao $\mathrm{H}$ and Sun $\mathrm{X}$ : Hydrogen-rich saline protects myocardium against ischemia/reperfusion injury in rats. Exp Biol Med (Maywood) 234: 1212-1219, 2009.

22. Tao J, Zhang J, Ling Y, McCall CE and Liu TF: Mitochondrial sirtuin 4 resolves immune tolerance in monocytes by rebalancing glycolysis and glucose oxidation homeostasis. Front Immunol 9: $419,2018$.

23. Livak KJ and Schmittgen TD: Analysis of relative gene expression data using real-time quantitative PCR and the 2(-Delta Delta C(T)) method. Methods 25: 402-408, 2001

24. Mehta LS, Beckie TM, Devon HA, Grines CL, Krumholz HM, Johnson MN, Lindley KJ, Vaccarino V, Wang TY, Watson KE, et al: Acute myocardial infarction in women: A scientific statement from the American Heart Association. Circulation 133: 916, 2016.

25. Toggweiler S, Sabti Z and Cuculi F: Prehospital ticagrelor in ST-segment elevation myocardial infarction. South China J Cardiol 9: 657-659, 2016.

26. RupareliaN,Godec J,LeeR,ChaiJT,Dall'ArmellinaE,McAndrewD, Digby JE, Forfar JC, Prendergast BD, Kharbanda RK, et al: Acute myocardial infarction activates distinct inflammation and proliferation pathways in circulating monocytes, prior to recruitment, and identified through conserved transcriptional responses in mice and humans. Eur Heart J 36: 1923-1934, 2015.

27. Prabhu SD and Frangogiannis NG: The biological basis for cardiac repair after myocardial infarction: From inflammation to fibrosis. Circ Res 119: 91-112, 2016.
28. Shin YM, Jung HJ, Choi WY and Lim CJ: Antioxidative, antiinflammatory, and matrix metalloproteinase inhibitory activities of 20(S)-ginsenoside $\operatorname{Rg} 3$ in cultured mammalian cell lines. Mol Biol Rep 40: 269-279, 2013.

29. Lee IS, Uh IJ, Kim KS, Kim KH, Park J, Kim Y, Jung JH, Jung HJ and Jang HJ: Anti-inflammatory effects of ginsenoside Rg3 via NF- $\kappa$ B pathway in A549 cells and human asthmatic lung tissue. J Immunol Res 2016: 7521601, 2016.

30. Brasier AR: The nuclear factor-kappaB-interleukin-6 signalling pathway mediating vascular inflammation. Cardiovasc Res 86 211-218, 2010.

31. Khanna AK, Jianping X and Mehra MR: Antioxidant N-acetyl cysteine reverses cigarette smoke-induced myocardial infarction by inhibiting inflammation and oxidative stress in a rat model. Lab Invest 92: 224-235, 2012.

32. Annacker O, Pimenta-Araujo R, Burlen-Defranoux $O$, Barbosa TC, Cumano A and Bandeira A: CD $25^{+} \mathrm{CD}^{+} \mathrm{T}$ cells regulate the expansion of peripheral $\mathrm{CD} 4 \mathrm{~T}$ cells through the production of IL-10. J Immunol 166: 3008-3018, 2001.

33. Dardalhon V, Awasthi A, Kwon H, Galileos G, Gao W, Sobel RA, Mitsdoerffer M, Strom TB, Elyaman W, Ho IC, et al: IL-4 inhibits TGF-beta-induced Foxp $3^{+} \mathrm{T}$ cells and, together with TGF-beta, generates IL- $9^{+}$IL-10 ${ }^{+}$Foxp3(-) effector T cells. Nat Immunol 131:1347-1355, 2008

34. Timóteo RP, Silva AF, Micheli DC, Candido Murta EF, Freire M, Teodoro RB,Lima FM, Martins Tavares Murta B and Bertoncello D: Increased flexibility, pain reduction and unaltered levels of IL-10 and $\mathrm{CD} 11 \mathrm{~b}+$ lymphocytes in patients with systemic lupus erythematosus were associated with kinesiotherapy. Lupus 27: 1159-1168, 2018.

35. Fujii S and Lotze MT: Interleukin-10 (IL-10). Cancer Drug Discov Dev: 165-179, 2007

36. Dambuza IM, He C, Choi JK, Yu CR, Wang R, Mattapallil MJ, Wingfield PT, Caspi RR and Egwuagu CE: IL-12p35 induces expansion of IL-10 and IL-35-expressing regulatory B cells and ameliorates autoimmune disease. Nat Commun 8: 719, 2017.

37. Groux $\mathrm{H}$ and Cottrez F: The complex role of interleukin-10 in autoimmunity. J Autoimmun 20: 281-285, 2003.

38. Lai M, Du G, Shi R, Yao J, Yang G, Wei Y, Zhang D, Xu Z, Zhang R, Li Y, et al: miR-34a inhibits migration and invasion by regulating the SIRT1/p53 pathway in human SW480 cells. Mol Med Rep 11: 3301-3307, 2015.

39. LI X and Jiang W: GW26-e0454 renalase protects the cardiomyocytes of Sprague-Dawley rats against ischemia and reperfusion injury by reducing myocardial cell necrosis and apoptosis. J Am Coll Cardiol 66: C43-C43, 2015.

40. Kim EK and Choi EJ: Compromised MAPK signaling in human diseases: An update. Arc Toxicol 89: 867-882, 2015.

41. Wagner SA, Satpathy S, Beli P and Choudhary C: SPATA2 links CYLD to the TNF- $\alpha$ receptor signaling complex and modulates the receptor signaling outcomes. EMBO J 35: 1868-1884, 2016.

42. Baker R, Hayden M and Ghosh S: NF- $\kappa B$, inflammation, and metabolic disease. Cell Metab 13: 11-22, 2011.

43. Ghosh S and Hayden MS: New regulators of NF-kappaB in inflammation. Nat Rev Immunol 8: 837-848, 2008.

This work is licensed under a Creative Commons Attribution-NonCommercial-NoDerivatives 4.0 International (CC BY-NC-ND 4.0) License. 